\title{
Article \\ Effect of Pulsed-Plasma Treatment on the Structural-Phase Composition and Tribological Properties of Detonation Coatings Based on Ti-Si-C
}

\author{
Bauyrzhan Rakhadilov ${ }^{1,2}$, Dastan Buitkenov ${ }^{1, * \mathbb{D}}$, Zhanat Idrisheva ${ }^{3}\left(\mathbb{D}\right.$, Manira Zhamanbayeva ${ }^{3}$, \\ Sapargali Pazylbek ${ }^{4}$ and Daryn Baizhan ${ }^{1,5}$ \\ 1 Research Center "Surface Engineering and Tribology", Sarsen Amanzholov East Kazakhstan University, \\ Ust-Kamenogorsk 070000, Kazakhstan; rakhadilovb@mail.ru (B.R.); daryn.baizhan@mail.ru (D.B.) \\ 2 PlasmaScience LLP, Ust-Kamenogorsk 070010, Kazakhstan \\ 3 School of Metallurgy and Mineral Processing, Daulet Serikbaev East Kazakhstan Technical University, \\ Ust-Kamenogorsk 070002, Kazakhstan; zhanat.idr@mail.ru (Z.I.); manogk@mail.ru (M.Z.) \\ 4 Department of Physics, South Kazakhstan State Pedagogical University, Shymkent 160005, Kazakhstan; \\ pazylbek.sapargali@yandex.kz \\ 5 Institute for Composite Materials, Ust-Kamenogorsk 070010, Kazakhstan \\ * Correspondence: buitkenovd@mail.ru; Tel.: +7-776-439-99-94
}

Citation: Rakhadilov, B.; Buitkenov, D.; Idrisheva, Z.; Zhamanbayeva, M.; Pazylbek, S.; Baizhan, D. Effect of Pulsed-Plasma Treatment on the Structural-Phase Composition and Tribological Properties of Detonation Coatings Based on Ti-Si-C. Coatings 2021, 11, 795. https://doi.org/ 10.3390/coatings11070795

Academic Editors: Yunn-Lin Hwang, Shih-Chen Shi and Jason Hsiao Chun Yang

Received: 25 May 2021

Accepted: 25 June 2021

Published: 1 July 2021

Publisher's Note: MDPI stays neutra with regard to jurisdictional claims in published maps and institutional affiliations.

Copyright: (c) 2021 by the authors. Licensee MDPI, Basel, Switzerland. This article is an open access article distributed under the terms and conditions of the Creative Commons Attribution (CC BY) license (https:// creativecommons.org/licenses/by/ $4.0 /)$
Abstract: The structural-phase state and tribological characteristics of detonation coatings based on Ti-Si-C before and after pulsed-plasma exposure have been experimentally investigated. The authors of the research used a detonation set-up of CCDS2000 to obtain coatings. The modification of coating surfaces was carried out by a pulsed-plasma flow using the "Impulse-6" installation. The results of the research have shown that the modification of coatings surface by a pulsed-plasma effect causes an increase in the microhardness of the surface layer and in its wear resistance. It was determined that after such type of treatment, there is an increase in the content of the $\mathrm{Ti}_{3} \mathrm{SiC}_{2}$ phase. According to the results of XRD analysis, the improvement in the mechano-tribological properties of detonation spraying coatings of the $\mathrm{Ti}-\mathrm{Si}-\mathrm{C}$ system as a result of pulsed-plasma treatment is associated with an increase in the content of $\mathrm{Ti}_{3} \mathrm{SiC}_{2}$ phases in the coatings, as well as the formation of carbide and oxide phases on the surface layer.

Keywords: detonation spraying; pulsed-plasma treatment; structure; phase; microhardness; wear resistance

\section{Introduction}

The detonation coatings have been widely used [1-4] to increase the wear resistance and corrosion resistance of machine parts, as well as to improve their physical and mechanical properties. At the same time, coatings based on the MAX phase have been widely studied due to their unique properties, such as the resistance to oxidation, the ease of processing, relatively low cost of materials, the excellent thermal stability and wear resistance of materials [5]. Among them, a phase called the ternary silicocarbide $\mathrm{Ti}_{3} \mathrm{SiC}_{2}$, which later became the prototype of the whole kind and is the most studied to date, is of particular interest [6,7]. However, getting the coatings based on $\mathrm{Ti}_{3} \mathrm{SiC}_{2}$ by the detonation method is usually accompanied by the formation of Ti-C and Ti-Si phases [8,9]. The short reaction time of powder mixtures and the decomposition of Ti-Si-C at high temperatures are the main problems for the clearance of phase [10]. As the results showed [9,11], high temperature, pressure and velocity of detonation products led to strong decomposition of $\mathrm{Ti}_{3} \mathrm{SiC}_{2}$ powders with the formation of a large amount of $\mathrm{TiC}$ phase. At the same time, by selecting the optimal degree of filling the barrel of detonation with an explosive acetylene-oxygen mixture, it is possible to control the content of $\mathrm{Ti}_{3} \mathrm{SiC}_{2}$ in the coatings on a certain level [12]. However, the volumetric fraction of the $\mathrm{Ti}_{3} \mathrm{SiC}_{2}$ phase will be rather 
low $(25-29 \%)$, mainly due to the short time of reaction of the mixture Ti-Si-C [13]. An increase in the volumetric fraction of $\mathrm{Ti}_{3} \mathrm{SiC}_{2}$ provides high mechanical and tribological properties of the composites. The content of the $\mathrm{Ti}_{3} \mathrm{SiC}_{2}$ phase can be increased due to some extent through the use of thermal treatment [14]. Earlier, the authors of this work obtained experimental results on the effect of heat treatment on structural-phase changes and mechanical-tribological properties of detonation coatings of the Ti-Si-C system [15]. Preliminary results have shown that the composition phase of detonation coatings can be significantly changed depending on the heat annealing temperature. However, the volume of heat treatment has disadvantages that are associated with the softening of the substrate materials. The disadvantages of traditional thermal treatment methods can be overcome with the thermal activation of the surface by pulsed-plasma flows [16]. The advantages of pulsed-plasma technology are high heating and cooling rates of the material surface (104-108 $\left.\mathrm{Ks}^{-1}\right)$ and the possibility of creating layered structures with different phases of composition and, accordingly, with different physical and chemical characteristics [17]. There is also the possibility of a local impact on the product with pulsed plasma [18]. Thus, the pulsed-plasma technology allows controlling the surface layer in the process of changing. In the literature, there is still no general opinion on the nature of the effect of pulsed-plasma treatment on structural-phase transformations in coatings based on $\mathrm{Ti}-\mathrm{Si}-\mathrm{C}$, as well as the effect of this type of treatment on the mechanical and tribological properties of the materials. Therefore, the study of structural-phase transformations in coatings based on Ti-Si-C under the impact of a plasma flow and the study on the effect of the occurring changes of structural phases on the mechanical and tribological properties of these coatings are very relevant.

The aim of this work is to study the effect of pulsed-plasma treatment on the structuralphase composition and tribological properties of detonation coatings based on Ti-Si-C.

\section{Materials and Methods}

\subsection{Experiment Setup}

The Ti-Si-C-based coatings were obtained while using a CCDS2000 (Computer Controlled Detonation Spraying) detonation set-up (LIH SB RAS, Novosibirsk, Russia), in which detonation is realized inside the barrel in an explosive mixture formed as a result of flow-through supply of gas components through a specialized mixing device $[2,19]$. A schematic of a CCDS2000 equipment is presented in Figure 1. The principle is as follows [20,21]: A mixture of gases is fed directly from the gas cylinders through the valve block (9), which enters the combustion chamber (3). At the same time, a powder sample is provided from the powder dispenser 11 into the space of the barrel 10 under pressure; then, thanks to the ignition device 4 , ignition occurs. As a result, the mixture is detonated and moved towards the nozzle 14, where the particles being sprayed are picked up and accelerated along the way. As a result, coating (12) is formed on the substrate 13. The control unit 1 controls the entire spraying process, from the supply of combustible gases and powder dosing to the movement of the sprayed billet itself (13) using a 3D manipulator.

Surface modification of the coatings was carried out by pulsed-plasma flow using a plasma generator developed by the E. O. Paton Institute of Electric Welding at Nationals Academy of Science (NAS) of Ukraine [16,17]. A feature of this plasma generator is the possibility of commuting the electric current by the ionized region of the gas behind the detonation wavefront. This makes it possible to generate pulsed plasma with a frequency of $1-4 \mathrm{~Hz}$ and energy of up to $7 \mathrm{~kJ}$. The pulsed-plasma generator (Figure 2) consists of a detonation chamber (1), where the combustion of combustible gas mixture $\left(\mathrm{C}_{3} \mathrm{H}_{8}, \mathrm{O}_{2}\right.$, air) is initiated, and coaxial electrodes $(2,3)$. If it is necessary to introduce alloying elements into the plasma in the form of vapor drop phase, an erodible electrode (4) is used. When an electric current flows behind the detonation wave (5), Joule heat is released in the interelectrode gap, thereby enhancing the accelerating plasma force's electromagnetic and gas-dynamic components. The energy characteristics of the plasma jets at the output of the pulsed-plasma device depend on the geometry of the coaxial electrodes and the electric field 
strength in the interelectrode gap. When the electric field strength between the electrodes is $3.5 \times 10^{5} \mathrm{~V} / \mathrm{m}$, the plasma velocity at the exit from the plasma torch reaches $4 \mathrm{~km} / \mathrm{s}$, and the temperature is $12,000 \mathrm{~K}$. At the moment of the interaction of the plasma pulse with the surface of the product (6), a region of shock-compressed plasma layer is formed in the contact zone. The electrical circuit between the eroded electrode and the product closes up. The current density reaches $10,000 \mathrm{~A} / \mathrm{cm}^{2}$. As a result, the surface undergoes multiple impacts, including thermal with a power density of $10^{4}$ up to $10^{6} \mathrm{~W} / \mathrm{cm}^{2}$, chemical and electromagnetic (magnetic field strength up to $4 \times 10^{5} \mathrm{~A} / \mathrm{m}$ ). Repeated exposure (thermal cycling) allows changing the surface's physical and mechanical properties due to structural transformations [18].

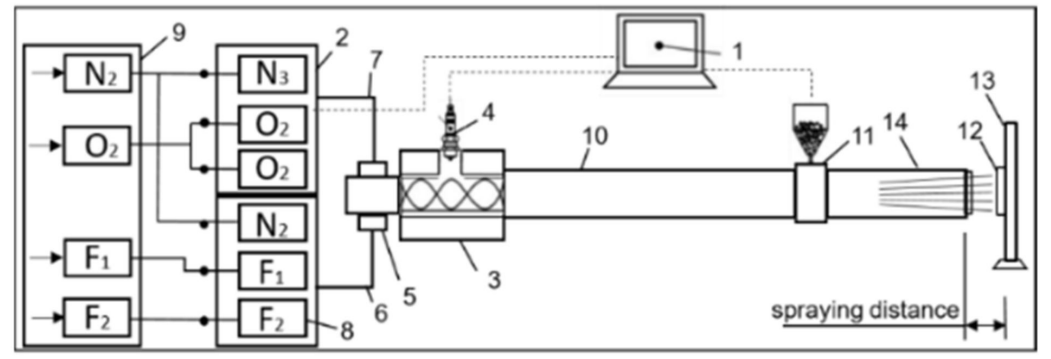

Figure 1. Schematic diagram of the computer-controlled detonation spraying set-up CCDS2000: 1-control computer; 2-gas distributor; 3-mixing-ignition chamber; 4-spark plug; 5-barrel valve; 6-fuel line; 7-oxygen line; 8-gas valves; 9-gas supply unit; 10-indicated part of the barrel; 11-powder feeder; 12 -workpiece; 13 -manipulator; 14 - the muzzle of the barrel; $\mathrm{F}_{1}$-acetylene; $\mathrm{F}_{2}$ - propane-butane; $\mathrm{O}_{2}$-oxygen; $\mathrm{N}_{2}$ - nitrogen.

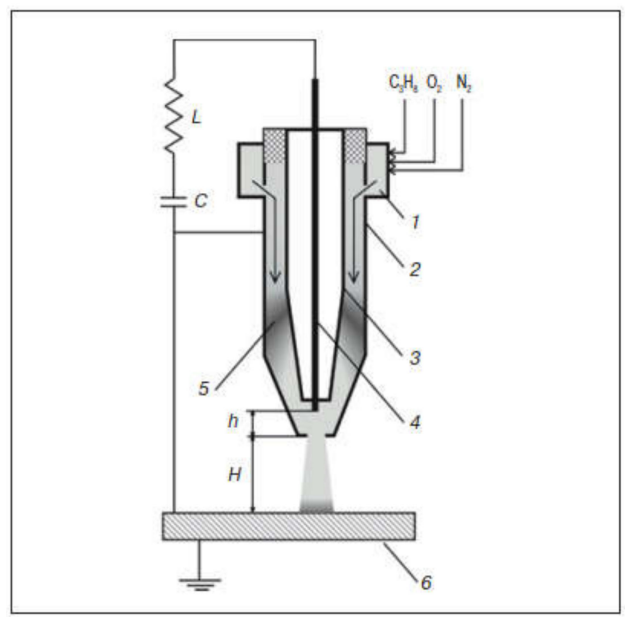

Figure 2. Pulsed-plasma device scheme [16] 1-detonation chamber; 2, 3-coaxial electrodes; 4consumable electrode; 5 -detonation wave; 6 - treating part.

\subsection{Stand for Testing Samples}

The research phase composition of the samples was studied by X-ray diffractometer $X^{\prime}$ PertPro (Philips Corporation, Netherlands) using $\mathrm{CuK} \alpha$ radiation. Data processing and quantitative analysis were performed using PowderCell 2.4. The surface morphology was studied by scanning electron microscopy on a Jeol 6390 scanning electron microscope with an electron-probe attachment for local microanalysis (Jed2300 energy dispersive spectrometer (EDS)). The Vickers microhardness of the samples was measured by a diamond indenter on a Metolab-502 (Metolab, Russia) device in accordance with GOST 9450-76, at a load of $200 \mathrm{~g}$ and an exposure time of $10 \mathrm{~s}$. The surface roughness of the coatings was estimated using the $\mathrm{R}_{\mathrm{a}}$ parameter by profilometer model 130 (JSC Plant PROTON, Russia). Tribological tests for dry sliding wear were performed on a high-temperature tribometer TRB ${ }^{3}$ (Anton Paar Srl, Peseux, Switzerland). Sample tests for abrasive wear were carried out 
on an experimental stand (Figure 3a) against soft fixed abrasive particles according to the "rotating roller-flat surface" scheme in accordance with GOST 23.208-79, which conforms to the American standard ASTM C 6568. Sample tests for impact and abrasive wear were carried out on an experimental stand in accordance with GOST 23.207-79 (Figure 3b).
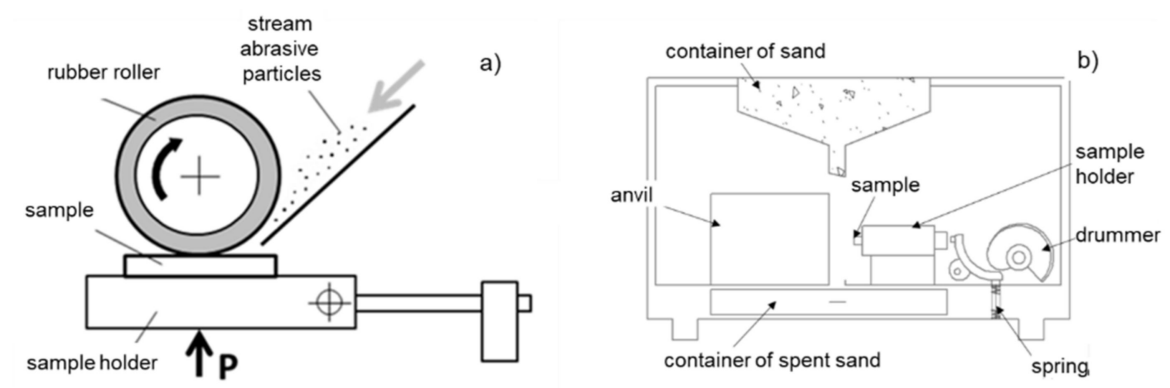

Figure 3. The experimental test stand for testing of samples: (a) abrasive wear according to the "rotating roller-flat surface" scheme; (b) impact and abrasive wear.

\subsection{Plan of Experiment}

To obtain detonation coatings based on $\mathrm{Ti}-\mathrm{Si}-\mathrm{C}$, we used a $\mathrm{Ti}_{3} \mathrm{SiC}_{2}$ powder with a particle size was between 20 and $40 \mu \mathrm{m}$. The acetylene-oxygen mixture, which is the most used fuel during the detonation of spraying powder materials, was used as a fuel gas. Spraying was carried out at the ratio of the acetylene-oxygen mixture $\mathrm{O}_{2} / \mathrm{C}_{2} \mathrm{H}_{2}=1.856$. The volume of the explosive barrel mixture of the detonation gun was $60 \%$. Nitrogen was used as a carrier gas. The distance between the sample treated surface and the detonation barrel was $200 \mathrm{~mm}$.

The detonation coatings were treated with a pulsed-plasma jet under the following modes: capacitance of capacitors $960 \mu \mathrm{F}$, voltage $3.2 \mathrm{kV}$, inductance $3 \times 10^{-2} \mathrm{mH}$, electrode $\mathrm{W}$, frequency $1.2 \mathrm{~Hz}$, speed of passage $5 \mathrm{~mm} / \mathrm{s}$, electrode recess $\mathrm{h}=16 \mathrm{~mm}$, number of passes 1 .

The treatment modes were changed by varying the distance $\mathrm{H}$ from the plasmatron to the hardened surface (Table 1).

Table 1. Sample treatment modes.

\begin{tabular}{ccc}
\hline Coating & Number of Hardening Mode & Distance from Plasma Torch to Product, $\mathbf{H}, \mathbf{m m}$ \\
\hline \multirow{2}{*}{ Ti-Si-C } & 1 & 30 \\
& 2 & 40 \\
& 3 & 50 \\
\hline
\end{tabular}

\section{Results and Discussion}

This section presents the study results of the structural and phase composition of detonation coatings based on Ti-Si-C before and after exposure to pulsed plasma. The mechanical and tribological properties of these coatings as a dependence on the distance from the plasmatron are investigated.

\subsection{Coating Microstructure}

Figure 4 shows the microstructure of the surface and cross-section of a sample of detonation coatings based on titanium carbosilicide. The coating has a typical structure characteristic of gas thermal spraying methods. The coating is characterized by the presence of high density and uniformity as well as the presence of individual pores. The interface between the coating and the base has a characteristic zigzag appearance. 

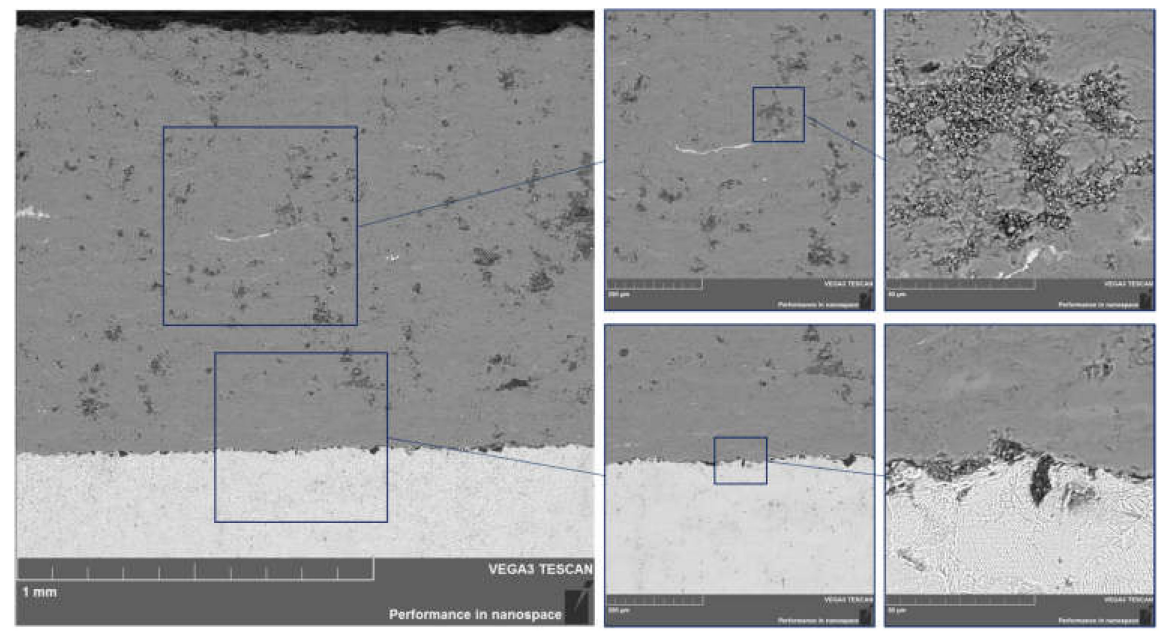

Figure 4. SEM image of the cross-section of the initial coating on based $\mathrm{Ti}_{3} \mathrm{SiC}_{2}$.

The microstructure of the cross-section of the coating after pulsed-plasma treatment depending on the distance from the plasmatron is shown in Figure 5. The upper layer contains a molten, plasma-modified extremal layer 20-25 $\mu \mathrm{m}$ in thickness (Figure 5). As a result of pulsed-plasma treatment, the chemical composition of the surface of the Ti-Si-C coatings was changed.

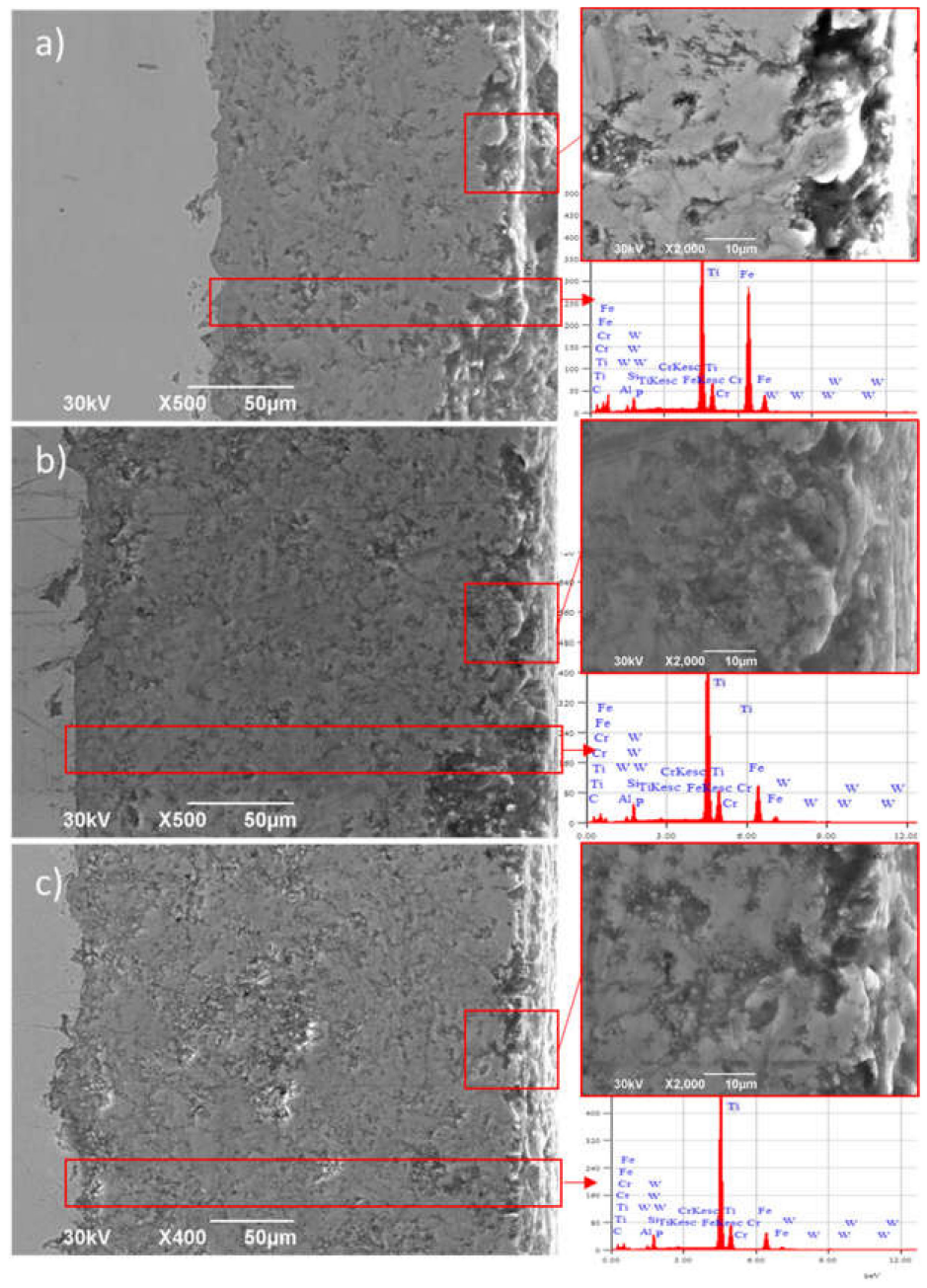

Figure 5. SEM images of the morphology of the cross-section of the Ti-Si-C coating after pulsedplasma treatment depending on the distance from the plasmatron: (a) $30 \mathrm{~mm}$, (b) $40 \mathrm{~mm}$, (c) $50 \mathrm{~mm}$. 
From the analysis of the energy-dispersive X-ray spectroscopy (EDX) spectrum taken from the surfaces of the coatings after the pulsed-plasma treatment, it can be concluded that their main components are $\mathrm{Ti}, \mathrm{Si}$ and $\mathrm{C}$. The presence of $\mathrm{W}$ was also recorded on the surface of the coating after the pulsed-plasma treatment. Considering that tungsten was identified as an eroded electrode particle and that during processing the electrode evaporated and tungsten particles were present in the plasma jet, its presence on the coating surface is natural.

\subsection{Microhardness $H V$}

The Vickers microhardness of Ti-Si-C detonation sprayed coatings before and after the pulsed-plasma impact are shown in Figure 6. The treated coatings in general were characterized by high microhardness in comparison with the original coating. At the same time, it strongly depends on the distance from the plasmatron to the surface of the coating. High hardness was observed on the coating surface treated at a distance of $50 \mathrm{~mm}$, and as the plasma torch approaches the surface being treated, the hardness decreases. Perhaps, in this case, this is due to an increase in the density of the energy flux falling on the sample surface. Therefore, another structural-phase state is formed in the near-surface layer.
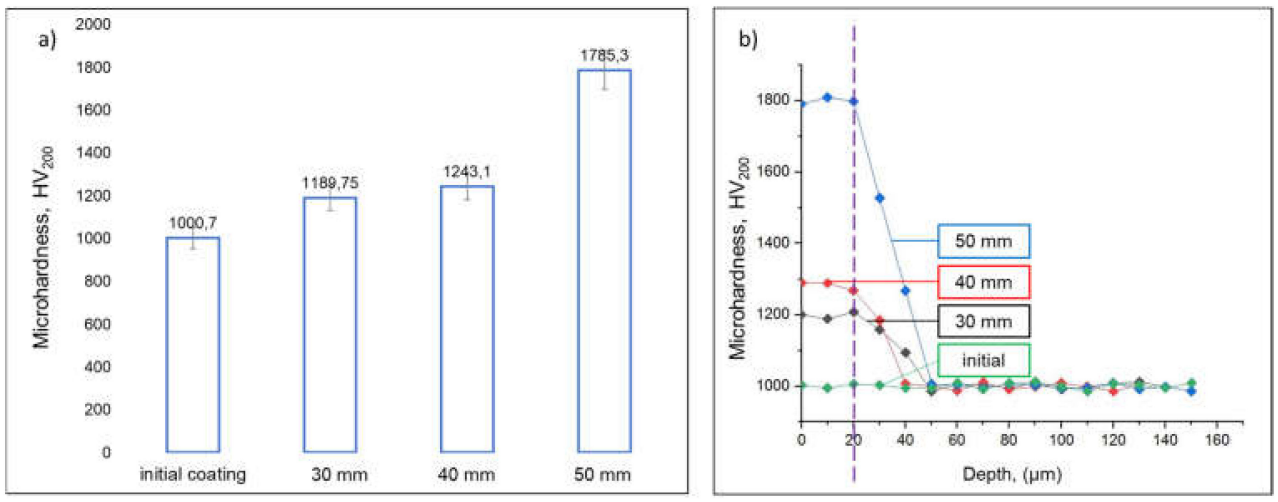

Figure 6. Surface microhardness (a) and the cross-section of detonation coatings based on Ti-Si-C (b) before and after pulsed-plasma treatment, depending on the distance from the plasmatron.

The hardness measurements over the cross-section of the surface layer are shown in Figure $6 \mathrm{~b}$. The figure shows that the microhardness value of the surface layer of all coatings is greater than that of the original coating, which indicates the surface hardening. The depth of the hardened layer is 20-30 $\mu \mathrm{m}$. Below this layer, the microhardness is reduced to the value ca. $1000 \mathrm{HV}$ and remains at this level throughout the entire depth of the coatings, that is, as in the initial state.

Figure 7 shows the results of measuring the surface roughness of coatings before and after pulsed-plasma treatment, depending on the distance from the plasmatron. In general, the treated surface has an irregular microrelief. It should also be noted that, in addition to the pores, the nature of the surface roughness depends on such indicators of the structure quality as the degree of molten powder particles and the strength of the cohesive bond between them. 


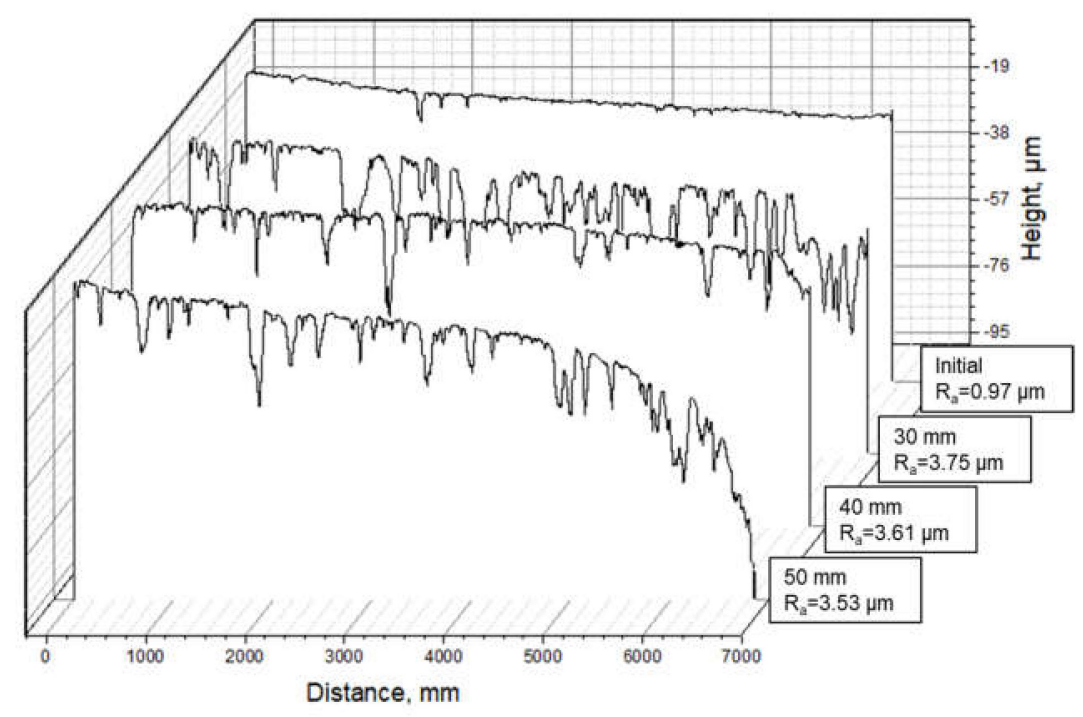

Figure 7. Surface roughness of the coating before and after pulsed-plasma treatment, depending on the distance from the plasma torch.

\subsection{XRD Analysis}

In order to identify the reasons for the change in microhardness, $X$-ray diffraction (XRD) analysis of the coatings before and after the pulsed-plasma treatment was carried out. Figure 8 shows diffractograms of the initial coatings of the Ti-Si-C system and those treated with pulsed-plasma exposure, depending on the distance of the plasmatron from the treated surface. The results of XRD analysis of the coatings showed that the initial coating consists of $\mathrm{TiC}$ phases as the main phases and $\mathrm{Ti}_{3} \mathrm{SiC}_{2}$ as the secondary phase. After the pulsed-plasma treatment, the phase composition did not change significantly, but the relative intensity of the peaks changed significantly. After treatment with pulsed-plasma exposure, an increase in the intensity of the peaks of all reflections is observed, as is the appearance of new reflections $(101,102,112,204,1110,0016)$ of the $\mathrm{Ti}_{3} \mathrm{SiC}_{2}$ phase, which indicates an increase in the content of the $\mathrm{Ti}_{3} \mathrm{SiC}_{2}$ phase in the coatings. An increase in the content of $\mathrm{Ti}_{3} \mathrm{SiC}_{2}$ phases is associated with heating above and rapid cooling of the samples during processing. A change in the proportion of phases indicates a solidphase transformation during pulsed-plasma activation. In addition, the coatings contain insignificant amounts of carbide and oxide phases: $\mathrm{WC}, \mathrm{TiO}_{2}$. This is due to the fact that the consumable electrode material penetrates into the hardened layer of the product. For example, in [22], when using a consumable electrode made of titanium, it was found in a hardened layer at a depth of $20 \mu \mathrm{m}$. In all coatings, an oxide film is present on the surface, mainly of the natural $\mathrm{TiO}_{2}$ oxide (rutile). The samples were processed in an air environment, which led to the formation of an oxide film. 


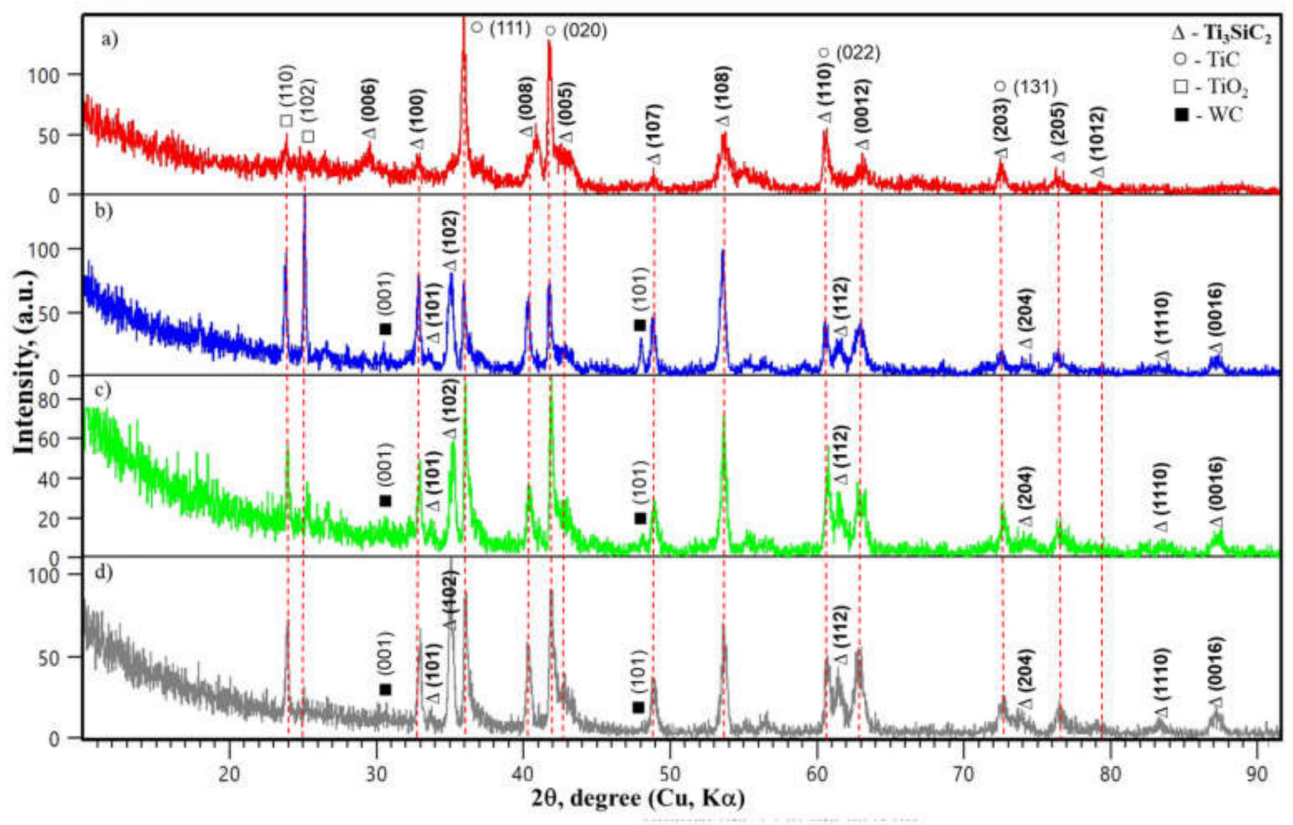

Figure 8. Diffractograms of detonation coatings based on Ti-Si-C before (a) and after pulsed-plasma treatment depending on the distance from the plasmatron: (b) $30 \mathrm{~mm}$, (c) $40 \mathrm{~mm}$, (d) $50 \mathrm{~mm}$.

Quantitative analyses were performed using PowderCell 2.4. Table 2 shows the data of X-ray phase analysis.

Table 2. Results of X-ray phase analysis.

\begin{tabular}{|c|c|c|c|c|c|}
\hline \multirow{2}{*}{ Sample Name } & \multirow{2}{*}{ Detected Phases } & \multicolumn{2}{|c|}{ Phase Structure Data in the Powder Cell Database } & \multirow{2}{*}{ Structure Type } & \multirow{2}{*}{ Phase Content wt. $\%$} \\
\hline & & Grid Type & Spatial Group & & \\
\hline \multirow{3}{*}{$\mathrm{Ti}_{3} \mathrm{SiC}_{2}$} & $\mathrm{Ti}_{3} \mathrm{SiC}_{2}$ & hexagonal & $\mathrm{P} 63 / \mathrm{mmc}(194)$ & $\mathrm{D}_{6 \mathrm{~h}}^{4}$ & 39 \\
\hline & $\mathrm{TiC}$ & cubic & Fm-3m (196) & $\mathrm{O}_{\mathrm{h}}^{5}$ & 57 \\
\hline & $\mathrm{TiO}_{2}$ & tetragonal & I41amd (141) & $\mathrm{D}_{4 \mathrm{~h}} 19$ & 4 \\
\hline \multirow{4}{*}{$\mathrm{Ti}_{3} \mathrm{SiC}_{2}$ after PPT $(30 \mathrm{~mm})$} & $\mathrm{Ti}_{3} \mathrm{SiC}_{2}$ & hexagonal & P63/mmc (194) & $\mathrm{D}_{6 \mathrm{~h}}^{4}$ & 52 \\
\hline & $\mathrm{TiC}$ & cubic & Fm-3m (196) & $\mathrm{O}^{5}$ & 29 \\
\hline & $\mathrm{TiO}_{2}$ & tetragonal & I41amd (141) & $\mathrm{D}_{4 \mathrm{~h}} 19$ & 9 \\
\hline & WC & hexagonal & P-6m2 (187) & $\mathrm{D}_{3 \mathrm{~h}} 1$ & 10 \\
\hline \multirow{4}{*}{$\mathrm{Ti}_{3} \mathrm{SiC}_{2}$ after PPT $(40 \mathrm{~mm})$} & $\mathrm{Ti}_{3} \mathrm{SiC}_{2}$ & hexagonal & $\mathrm{P} 63 / \mathrm{mmc}(194)$ & $\mathrm{D}_{6 \mathrm{~h}}^{4}$ & 59 \\
\hline & $\mathrm{TiC}$ & cubic & $\mathrm{Fm}-3 \mathrm{~m}(196)$ & $\mathrm{O}^{5}{ }^{5}$ & 27 \\
\hline & $\mathrm{TiO}_{2}$ & tetragonal & I41amd (141) & $\mathrm{D}_{4 \mathrm{~h}} 19$ & 6 \\
\hline & WC & hexagonal & P-6m2 (187) & $\mathrm{D}_{3 \mathrm{~h}}{ }^{1}$ & 8 \\
\hline \multirow{4}{*}{$\mathrm{Ti}_{3} \mathrm{SiC}_{2}$ after PPT $(50 \mathrm{~mm})$} & $\mathrm{Ti}_{3} \mathrm{SiC}_{2}$ & hexagonal & P63/mmc (194) & $\mathrm{D}_{6 \mathrm{~h}}^{4}$ & 62 \\
\hline & $\mathrm{TiC}$ & cubic & Fm-3m (196) & $\mathrm{O}_{\mathrm{h}}^{5}$ & 27 \\
\hline & $\mathrm{TiO}_{2}$ & tetragonal & I41amd (141) & $\mathrm{D}_{4 \mathrm{~h}} 19$ & 6 \\
\hline & WC & hexagonal & P-6m2 (187) & $\mathrm{D}_{3 \mathrm{~h}} 1$ & 5 \\
\hline
\end{tabular}

According to the results of XRD analysis, an increase in the microhardness of detonation coatings of the Ti-Si-C system as a result of pulsed-plasma treatment is associated with an increase in the content of $\mathrm{Ti}_{3} \mathrm{SiC}_{2}$ phases in the coatings, as well as an increase in solid secondary phases or tungsten carbide particles.

\subsection{Wear Testing}

Figure 9 shows the curves of wear of coated Ti-Si-C before and after modification by plasma treatment, depending on the distance from the plasmatron. 


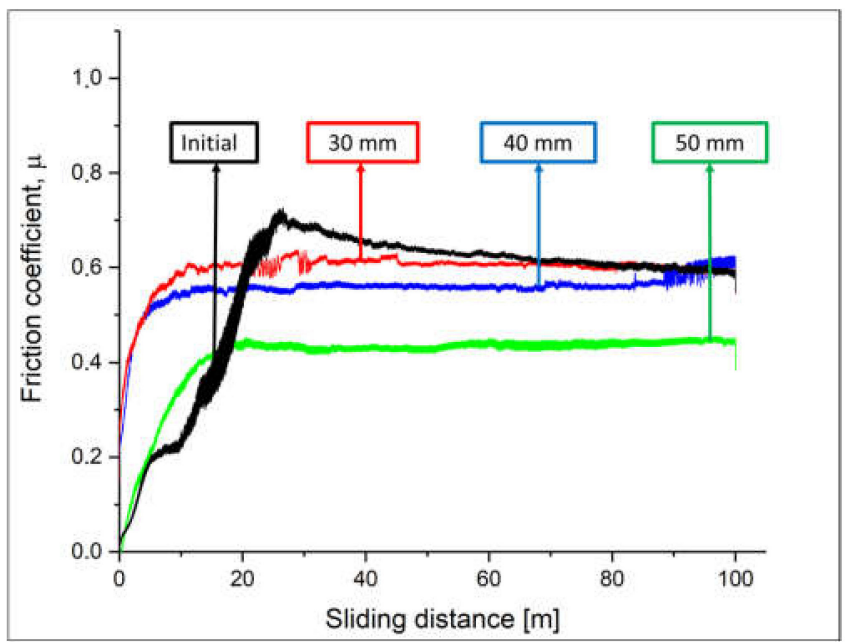

Figure 9. Results of tribological tests of Ti-Si-C coatings before (initial) and after pulsed-plasma treatment.

The experiment showed that after the pulsed-plasma treatment of the samples, the friction coefficient $\mu$ decreases (Figure 9). If the value of the friction coefficient in the initial Ti-Si-C coatings is 0.65 , then after the pulse treatment it decreases depending on the distance $\mathrm{H}$ from 0.60 up to 0.40 . The experiments carried out showed that pulsed-plasma treatment leads to an improvement in the tribological properties of Ti-Si-C coatings. This effect can be obtained by eliminating surface defects (microcracks and pores) and changing the structural-phase state of the coatings. A possible reason for the decrease in the friction coefficient may be an increase in microhardness. According to [23], the decrease in the friction coefficient correlates with the surface hardening. However, the friction coefficient value is not determined strictly by the hardness values since it is affected simultaneously by several surface characteristics during the friction process.

In order to evaluate the abrasive resistance of $\mathrm{Ti}-\mathrm{Si}-\mathrm{C}$ coatings and shock-abrasive wear, appropriate tests were carried out. Comparative studies of the wear resistance of coatings under friction in an abrasive medium have shown that coatings after modification by plasma treatment provide the highest wear resistance.

Figure 10 shows the results of abrasive and impact-abrasive wear tests. According to the results of determining the mass loss of samples after wear resistance tests for abrasive and shockabrasive wear, the coating processed at a distance of $50 \mathrm{~mm}$ has the highest wear resistance.

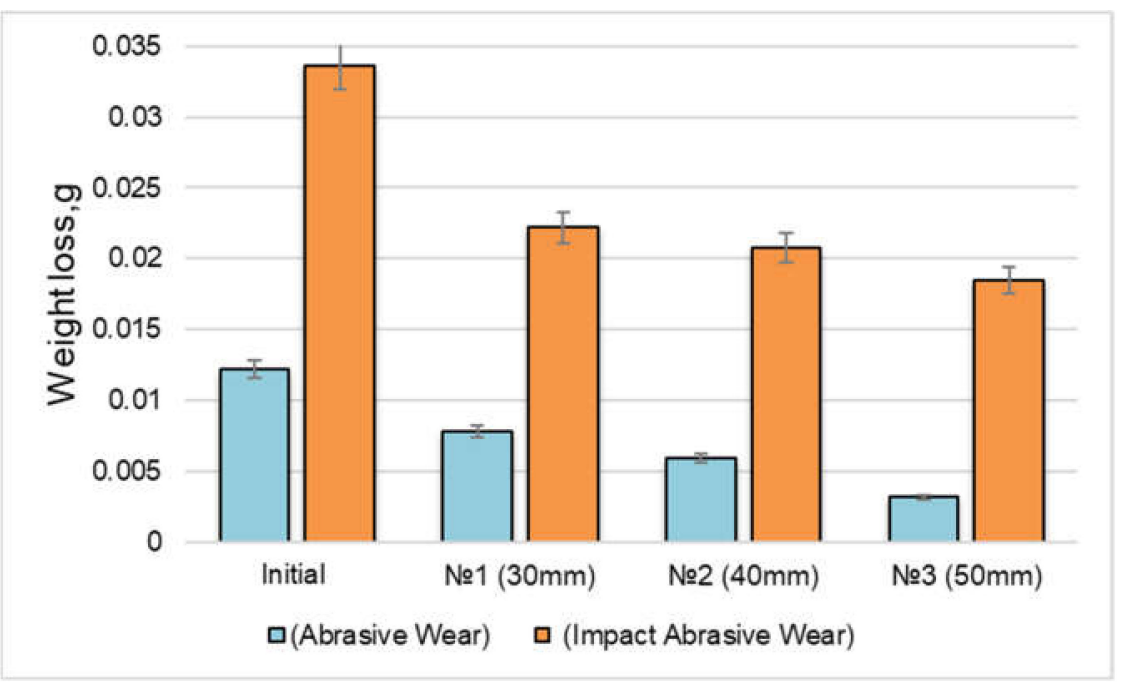

Figure 10. Results of testing abrasive and shock-abrasive wear before (initial) and after pulsed-plasma treatment, depending on the distance from the plasmatron. 
Thus, when detonation coatings based on Ti-Si-C are treated with pulsed plasma, a modified layer appears on the surface, which, in terms of its mechanical and tribological properties, is superior to the original surface.

\section{Conclusions}

The effect of modification by pulsed-plasma action of coatings based on Ti-Si-C obtained by the detonation method was studied. Pulsed-plasma treatment can be effective for changing the state of the outer layer of $\mathrm{Ti}_{3} \mathrm{SiC}_{2}$ coatings and, thus, can change their functional properties.

The performed X-ray phase analysis showed that, as a result of treatment with a pulsed-plasma effect, the content of the $\mathrm{Ti}_{3} \mathrm{SiC}_{2}$ phase increased from $39 \%$ to $62 \%$. According to the results of XRD analysis, it was found that an increase in the microhardness of detonation coatings of the Ti-Si-C system as a result of pulsed-plasma treatment is associated with an increase in the content of $\mathrm{Ti}_{3} \mathrm{SiC}_{2}$ phases in the coatings, as well as an increase in solid secondary phases or tungsten carbide particles. High hardness is observed on the coating surface treated at a distance of $50 \mathrm{~mm}$.

According to the results of determining the mass loss of samples after wear resistance tests for abrasive and shock-abrasive wear, the coating processed according to mode No. 3 at a distance of $50 \mathrm{~mm}$ has the highest wear resistance. Experiments have shown that pulsed-plasma treatment leads to an improvement in the tribological properties of $\mathrm{Ti}-\mathrm{Si}-$ $\mathrm{C}$ coatings. Based on the analysis of the parameters of the mechanical and tribological properties, the optimization of the modes of pulsed-plasma treatment of the detonation coating of the Ti-Si-C system was carried out. It is established that the optimal distances of pulsed-plasma treatment of detonation coatings for the Ti-Si-C system are $50 \mathrm{~mm}$.

Thereby, pulsed-plasma treatment is a highly productive process of surface modification, carried out without heating the entire product. This allows solving the problems of increasing the wear resistance of a specific surface without changing the structural state of the entire product.

Author Contributions: B.R. and D.B. (Dastan Buitkenov) designed the experiments; B.R., Z.I., D.B. (Daryn Baizhan) and M.Z. performed the experiments; B.R., D.B. (Dastan Buitkenov) and S.P. analyzed the data; B.R. and D.B. (Dastan Buitkenov) wrote, reviewed and edited the paper. All authors have read and agreed to the published version of the manuscript.

Funding: This paper was performed within the grant financing of scientific research of the Committee of Science of the Ministry of Education and Science of the Republic of Kazakhstan. Grant AP08857579 and Grant AP08857800.

Institutional Review Board Statement: Not applicable.

Informed Consent Statement: Not applicable.

Data Availability Statement: Data is contained within the article.

Conflicts of Interest: The authors declare that there is no conflict of interest regarding the publication of this manuscript.

\section{References}

1. Kuchumova, I.D.; Batraev, I.S.; Ulianitsky, V.Y.; Shtertser, A.A.; Gerasimov, K.B.; Ukhina, A.V.; Bulina, N.V.; Bataev, I.A.; Koga, G.Y.; Guo, Y.; et al. Formation of Metallic Glass Coatings by Detonation Spraying of a $\mathrm{Fe}_{66} \mathrm{Cr}_{10} \mathrm{Nb}_{5} \mathrm{~B}_{19}$ Powder. Metals 2019, 9 , 846. [CrossRef]

2. Ulianitsky, V.; Batraev, I.; Dudina, D.; Smurov, I. Enhancing the properties of WC/ Co detonation coatings using two-component fuels. Surf. Coat. Technol. 2017, 318, 244-249. [CrossRef]

3. Samodurova, M.; Shaburova, N.; Samoilova, O.; Moghaddam, A.O.; Pashkeev, K.; Ul'yanitckiy, V.; Trofimov, E. Properties of WC $-10 \% \mathrm{Co}-4 \% \mathrm{Cr}$ Detonation Spray Coating Deposited on the Al-4\%Cu-1\%Mg Alloy. Materials 2021, 14, 1206. [CrossRef] [PubMed]

4. Sun, Z.; Zhu, S.; Dong, W.; Ding, H.; Bai, Y.; Luo, Y.; Di, P. Geometric Influence of Hard Phase on Corrosion Performance between WC-Reinforced Coatings Prepared by High-Velocity Oxygen-Fuel Spray and Electric Contact Strengthening. Coatings 2021, 11, 694. [CrossRef] 
5. Barsoum, W. The Mn+1AXn: A new Class of Solids: Thermodynamically Stable Nanolaminates. Prog. Solid State Chem. 2000, 28, 201-281. [CrossRef]

6. Shi, Q.; Zhu, H.; Li, C. The Effects of the Addition of $\mathrm{Ti}_{3} \mathrm{SiC}_{2}$ on the Microstructure and Properties of Laser Cladding Composite Coatings. Coatings 2020, 10, 498. [CrossRef]

7. Xu, J.; Liu, L.L.; Jiang, L.; Munroe, P.; Xie, Z.H. Unraveling the mechanical and tribological properties of a novel $\mathrm{Ti}_{5} \mathrm{Si}_{3} / \mathrm{TiC}$ nanocomposite coating synthesized by a double glow discharge plasma technique. Ceram. Int. 2013, 39, 9471-9481. [CrossRef]

8. Benamor, A.; Hadji, Y.; Chiker, N.; Haddad, A.; Guedouar, B.; Labaiz, M.; Hakem, M.; Tricoteaux, A.; Nivot, C.; Erauw, J.P.; et al. Spark Plasma Sintering and tribological behavior of $\mathrm{Ti}_{3} \mathrm{SiC}_{2}-\mathrm{Ti}_{5} \mathrm{Si}_{3}-\mathrm{TiC}$ composites. Ceram. Int. 2019, 45, 21781-21792. [CrossRef]

9. Rakhadilov, B.K.; Buitkenov, D.B.; Tuyakbaev, B.T.; Sagdoldina, Z.B.; Kenesbekov, A.B. Structure and properties of detonation coatings based on titanium carbosilicide. In Key Engineering Materials; Trans Tech Publications Ltd.: Baech, Switzerland, 2019; pp. 301-306.

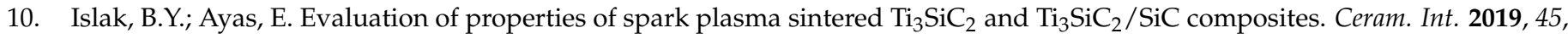
12297-12306. [CrossRef]

11. Buitkenov, D.B.; Rakhadilov, B.K.; Wieleba, W.; Kylyshkanov, M.K.; Yerbolatuly, D. Impact of the detonation gas spraying mode on the phase composition and adhesional strength of Ti-Si-C coatings. Bull. Univ. Karaganda Phys. 2020, 1, 59-64.

12. Li, C.; Yan, S.; Zhang, F.; He, J. Fabrication and characterization of micro-laminated $\mathrm{TiC}_{-} \mathrm{Ti}_{5} \mathrm{Si}_{3}-\mathrm{Ti}_{3} \mathrm{SiC}_{2}$ composite coatings by atmosphere plasma spraying. Vacuum 2019, 161, 14-20. [CrossRef]

13. Buitkenov, D.; Rakhadilov, B.; Erbolatuly, D.; Sagdoldina, Z. Influence of Heat Treatment on the Phase Composition and Microhardness of Coatings Based on $\mathrm{Ti}_{3} \mathrm{SiC}_{2}$ / TiC. In Key Engineering Materials; Trans Tech Publications Ltd.: Baech, Switzerland, 2020; Volume 839, pp. 137-143.

14. Buitkenov, D.; Rakhadilov, B.; Erbolatuly, D.; Sagdoldina, Z. Reserach of the mechanic-tribological characteristics of $\mathrm{Ti}_{3} \mathrm{SiC}_{2} / \mathrm{TiC}$ coatings after annealing. Eurasian J. Phys. Funct. Mater. 2020, 4, 86-89. [CrossRef]

15. Rakhadilov, B.; Buitkenov, D.; Sagdoldina, Z.; Seitov, B.; Kurbanbekov, S.; Adilkanova, M. Structural Features and Tribological Properties of Detonation Gun Sprayed Ti-Si-C Coating. Coatings 2021, 11, 141. [CrossRef]

16. Pogrebnjak, A.D.; Tyurin, Y.N.; Kobzev, A.P. High-Speed Plasma Jet Modification and Doping of $\alpha$-Fe. Tech. Phys. Lett. 2001, 27, 619-621. [CrossRef]

17. Zhadkevich, M.L.; Tyurin, Y.N.; Kolisnichenko, O.V. Impul'sno-plazmennoye uprochneniye instrumenta. Oborudovaniye Instrum. 2004, 04, 40-43. (In Russia)

18. Tyurin, Y.N.; Kolisnichenko, O.V. Plasma-detonation technology for modification of the surface layer of metal parts. Open Surf. Sci. J. 2009, 1, 13-19. [CrossRef]

19. Ulianitsky, V.; Shtertser, A.; Zlobin, S.; Smurov, I. Computer-controlled detonation spraying: From process fundamentals toward advanced applications. J. Therm. Spray Technol. 2011, 20, 791-801. [CrossRef]

20. Ulianitsky, V.Y.; Batraev, I.S.; Shtertser, A.A.; Dudina, D.V.; Bulina, N.V.; Smurov, I. Detonation spraying behaviour of refractory metals: Case studies for Mo and Ta-based powders. Adv. Powder Technol. 2018, 29, 1859-1864. [CrossRef]

21. Ulianitsky, V.Y.; Rybin, D.K.; Ukhina, A.V.; Bokhonov, B.B.; Dudina, D.V.; Samodurova, M.N.; Trofimov, E.A. Structure and composition of Fe-Co-Ni and Fe-Co-Ni-Cu coatings obtained by detonation spraying of powder mixtures. Mater. Lett. 2021, 290, 129498. [CrossRef]

22. Pogrebnjak, A.D.; Tyurin, Y.N. Modification of material properties and coating deposition using plasma jets. Physics-Uspekhi 2005, 48, 515-544.

23. Berkovich, I.I.; Gromakovskiy, D.G. Tribologiya. Fizicheskiye osnovy, mekhanika i tekhnicheskiye prilozheniya: Uchebnik dlya vuzov.; Samar. Gos. Tekhnicheskiy Univ: Samara, Russia, 2000; Volume 268, ISBN 5-7964-0164-5. (In Russia) 